\title{
Ocular Morbidity at High Altitude in Nepal
}

\section{Sabina Shrestha ${ }^{1}$, Aparajita Manoranjan ${ }^{1}$, Sushan Man Shrestha ${ }^{2}$}

${ }^{1}$ Nepal Eye Hospital, Kathmandu, Nepal. ${ }^{2}$ Manmohan Memorial Institute of Health Sciences, Kathmandu, Nepal.

\section{ABSTRACT}

Introduction: Certain changes occur in high altitude which can be organic, motor or functional. This study was conducted to find out ocular morbidity at high altitude in Nepal.

Methods: A cross sectional study was conducted at four different places at altitudes of 2710 m (Jomsom), $2900 \mathrm{~m}$ (Kagbeni), $3500 \mathrm{~m}$ (Jharkot) and $3800 \mathrm{~m}$ (Muktinath) of Mustang district of Nepal using convenient sampling method. A total of 222 subjects (444 eyes) were included. They were examined for vascular engorgement and tortuosity, arteriovenous ratio changes, retinal hemorrhages, cataract, pterygium, color vision and intraocular pressure. The motor changes like esodeviation and exodeviation were studied.

Results: Of the total 222 participants, 164 (77.5\%) were more than 40 years of age and 58 $(22.5 \%)$ were less than 40 years. The male to female ratio was $1: 1.1$. The duration of stay at high altitude was $>10$ years in $96.6 \%,>15$ years $88.3 \%$ and $>20$ years $83.8 \%$. The prevalence of cataract was $19.8 \%$ and pseudophakia $17.1 \%$. Other organic changes like venous engorgement, arterio-venous ratio changes and venous tortuosity was also found at high altitude. There was no significant change in intraocular pressure at high altitude. Esodeviation was present in $14 \%$. The prevalence of pterygium was present in $39.6 \%$. Similarly, the prevalence of red green color vision deficiency was $45.1 \%$.

Conclusion: Cataract, pterygium, red green color vision deficiency, esodeviation, venous engorgement and venous tortuosity were found to be prevalent at high altitude of Nepal.

Keywords: high altitude; ocular morbidity; Nepal

\section{INTRODUCTION}

Nepal is a mountainous country with $6.73 \%$ of the population residing in the mountainous region as per National Population and Housing Census, 2011. Several studies have been conducted about the acute changes in the eyes during the ascend at high altitude. However, this study was conducted to find the ocular changes in people residing at high altitude and it was a baseline study of ocular morbidity at high altitude in Nepal. There are certain organic, motor and functional changes in eyes that occur at high altitude. The organic changes are retinal venous engorgement, arterio-venous MJSBH Vol 15 Issue 2 July-Dec 2016 ratio changes, retinal haemorrhage, pailloedema and cataract. The motor changes are tendency towards esophoria. Similarly, functional changes are decrease in visual acuity, decreased color hue saturation, decreased stereopsis and the presence of pterygium ${ }^{1}$.

The study was aimed to find out the ocular morbidity at high altitude in Nepal.

Correspondence: Sabina Shrestha, Nepal Eye Hospital, Kathmandu, Nepal. Email: sabina_drs@hotmail.com 


\section{METHODS}

It was a descriptive cross-sectional study. The variables studied were causes of ocular morbidity, level of altitude, ethnicity, age, gender and duration of stay at high altitude. The study was conducted by Professional Support Service Nepal at Jomsom, Kagbeni, Jharkot and, Muktinath at an altitude of 2710 $\mathrm{m}$ (meters), $2900 \mathrm{~m}, 3500 \mathrm{~m}$ and $3800 \mathrm{~m}$ respectively. The target population were those residing at Jomsom, Kagbeni, Jharkot and Muktinath. A non-probability sampling method was used with the sample size of 222. The study was conducted from 2009 to 2010. Ethical clearance was taken from Nepal Health Research Council for the study and informed consent was taken from all the participants.

Eye screening camps were organized at Jomsom, Kagbeni, Jharkot and Muktinath. An especially designed proforma was used for data collection. Visual acuity testing was done using Snellen's chart. Anterior segment examination was done for the presence/absence of pterygium, cataract and pseudophakia. The patients were examined after pupillary dilatation with $1 \%$ tropicamide eye drop for organic changes like retinal venous engorgement, anteriovenous ratio changes, venous tortuosity and retinal hemorrhages.
Intraocular pressure was measured with Schiotz tonometer. Similarly, color vision was tested using Ishihara isochromatic chart and stereopsis was measured using Frisby steroacuity plates.

The data was entered in the computer and coding was done so that the confidentiality was maintained. Data analysis was done using the SPSS program (Version 11.0).

\section{RESULTS}

Among 222 participants enrolled in the study, 58 were examined at Jomsom at an altitude of 2710 m, 73 at Kagbeni at an altitude of 2900 $\mathrm{m}, 53$ at Jharkot at an altitude of $3500 \mathrm{~m}$ and 38 at Muktinath at an altitude of $3800 \mathrm{~m}$.

In all the four places (Jomsom, Kagbeni, Jharkot and Muktinath), patients above 40 years of age were more than $70 \%$ and female population was more than male population. The majority of the population had been residing in high altitude since birth. (Fig $1 \& 2$; and Table 1)

Regarding the organic changes, retinal venous engorgement was seen in $73 \%$. Similarly, arteiovenous ratio was $1: 3$ in $14 \%, 1.5: 3$ in $15.5 \%$ and $2: 3$ (normal) in $70.80 \%$ of cases. Venous tortuoity was present in $49.5 \%$ and retinal hemorrhage was present in $5.9 \%$ of

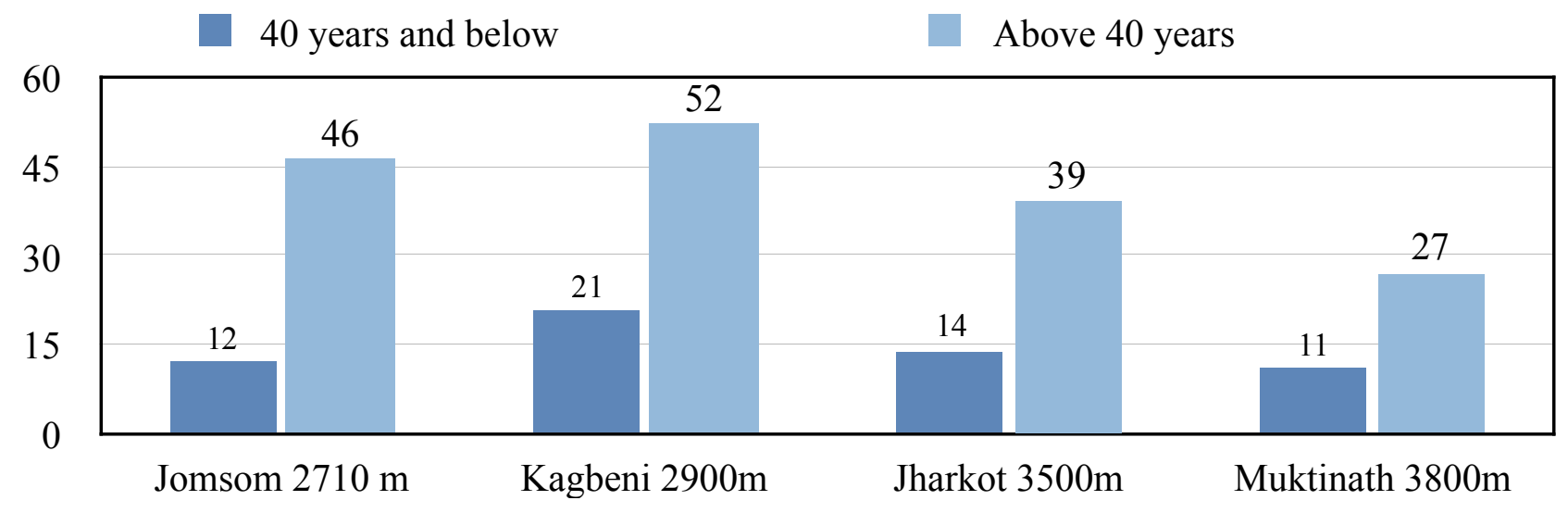

Figure 1: Distribution of the patients according to age 


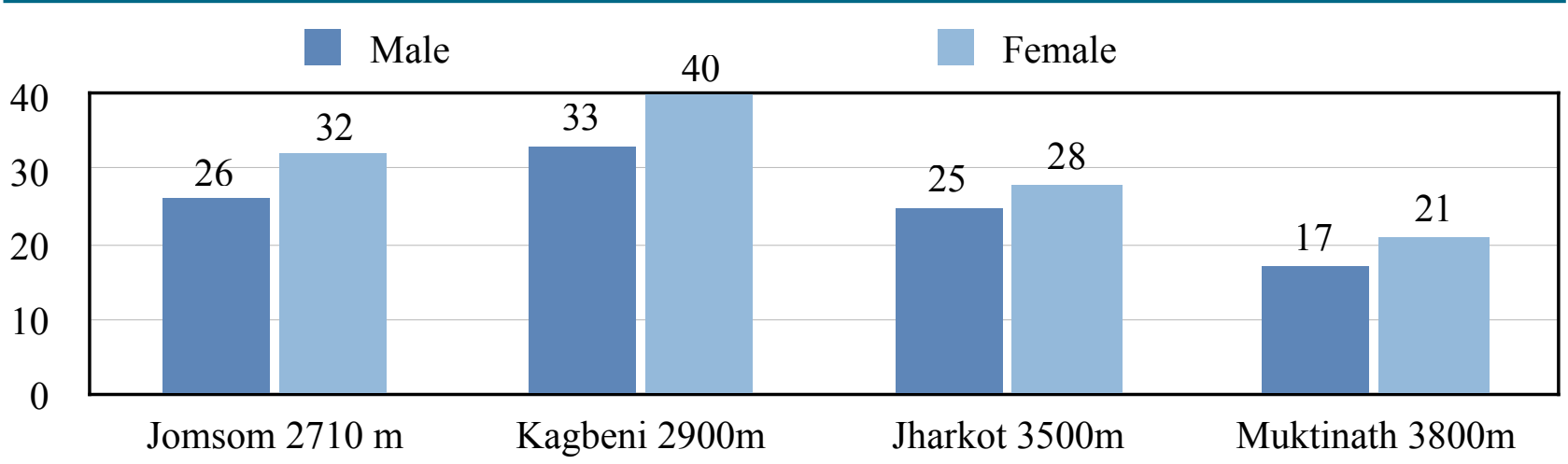

Figure 2: Distribution of the patients according to gender.

Table 1: Distribution of patients according to duration of stay at high altitude

\begin{tabular}{|c|c|c|c|c|}
\hline Duration in Years & Jomsom & Kagbeni & Jharkot & Muktinath \\
\hline 10 & $12 \%$ & $1 \%$ & $0 \%$ & $3 \%$ \\
\hline $11-20$ & $9 \%$ & $12 \%$ & $6 \%$ & $13 \%$ \\
\hline $20-30$ & $5 \%$ & $0 \%$ & $0 \%$ & $8 \%$ \\
\hline $30-40$ & $3 \%$ & $0 \%$ & $0 \%$ & $0 \%$ \\
\hline Since Birth & $71 \%$ & $86 \%$ & $94 \%$ & $76 \%$ \\
\hline
\end{tabular}

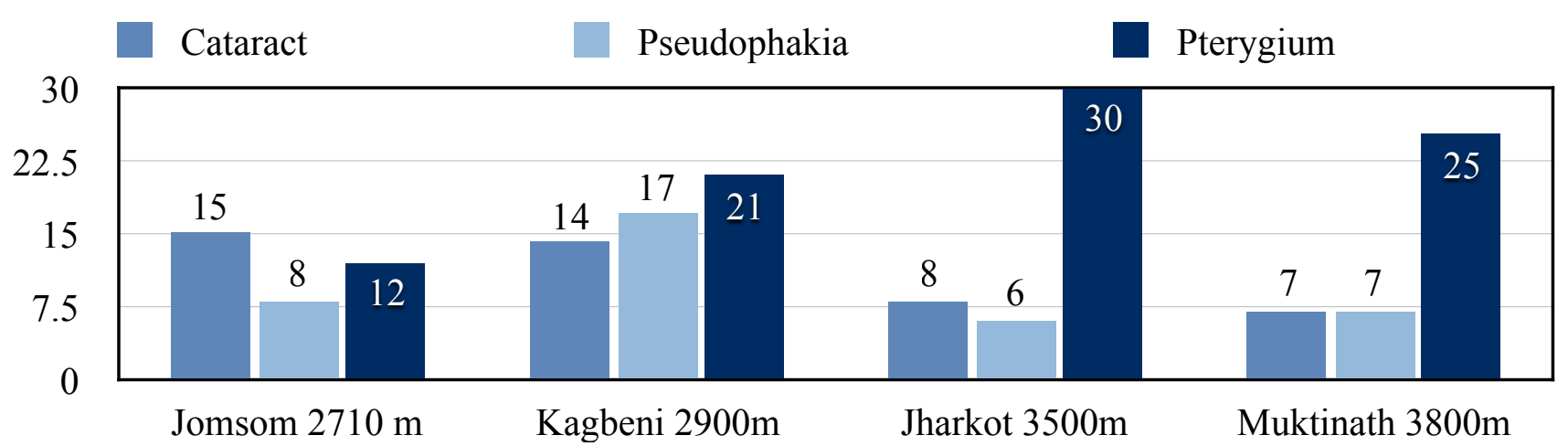

Figure 3: Distribution of Cataract, Pseudophakia and Pterygium in patients with altitude.

cases. Papilledema was absent in all the cases. The prevalence of cataract is found to be $19.8 \%$ (44 cases) at high altitude. Cataract was present in both eyes in $13.5 \%(n=13)$ and present in one eye in $6.3 \% \quad(n=14)$. The prevalence of pseudophakia is $17.1 \%$ at high altitude. The prevalence of cataract and pseudophakia with the rise in altitude is not statistically significant $(p$ value $>0.05)$. (Figure 3).
Intraocular pressure was found to be $=/<20.6$ $\mathrm{mm}$ of $\mathrm{Hg}$ in $100 \%$ at 2710 meters, $=/<20.6$ $\mathrm{mm}$ of $\mathrm{Hg}$ in $95.9 \%$ at 2900 meters, $=/<20.6$ $\mathrm{mm}$ of $\mathrm{Hg}$ in $100 \%$ at 3500 meters and $=/<20.6$ $\mathrm{mm}$ of $\mathrm{Hg}$ in $97.3 \%$ at 3800 meters. There was no significant change in intraocular pressure among people residing at high altitude.

The prevalence of pterygium is $39.6 \%(n=88)$ at high altitude. The prevalence of pterygium is 
Table 2: Distribution of patients according to motor changes (Esodeviation)

\begin{tabular}{|c|c|c|c|c|}
\hline Altitude & $\begin{array}{c}\text { Esophoria } \\
\text { Near }\end{array}$ & $\begin{array}{l}\text { Esophoria } \\
\text { Distance }\end{array}$ & Esotropia Near & $\begin{array}{c}\text { Esotropia } \\
\text { Distance }\end{array}$ \\
\hline Jomsom (2710 m) & 0 & 16 & 0 & 1 \\
\hline Kagbeni $(2900$ m) & 3 & 3 & 3 & 1 \\
\hline Jharkot (3500 m) & 1 & 0 & 0 & 0 \\
\hline Muktinath $(3800 \mathrm{~m})$ & 0 & 2 & 0 & 1 \\
\hline Total & 4 & 21 & 3 & 3 \\
\hline
\end{tabular}

Table 3: Distribution of patients according to functional changes (Stereopsis)

\begin{tabular}{|c|c|c|c|c|}
\hline Altitude & $\begin{array}{c}\text { Frequency } \\
\text { (seconds of arc) }\end{array}$ & Median & Minimum & Maximum \\
\hline Jomsom (2710 m) & 48 & 25.75 & 1.49 & 643.71 \\
\hline Kagbeni (2900 m) & 64 & 23.20 & 5.50 & 1661.19 \\
\hline Jharkot (3500 m) & 52 & 24.09 & 3.81 & 299.94 \\
\hline Muktinath $(3800 \mathrm{~m})$ & 34 & 38.61 & 6.33 & 602.18 \\
\hline
\end{tabular}

in increasing trend with the rise in altitude which is statistically significant $(\mathrm{p}$ value $=$ $0.000)$.

Among 222 participants, color vision was taken in 206 participants, out of which 113 (54.9\%) were found to be normal while 93 (45.1\%) had abnormal color vision (red green deficiency). Seventy three (35.4\%) had both eye involvement and $20(9.7 \%)$ had only one eye involved.

\section{DISCUSSION}

There are certain organic changes, motor changes and functional changes in the eyes at high altitude. Among organic changes, vascular changes are most important and permanent. Vascular engorgement is a permanent feature. It becomes apparent at $12000 \mathrm{ft}(3658 \mathrm{~m})$ and reaches its maximum at $18000 \mathrm{ft}(5486 \mathrm{~m})$. The arterio-venous ratio becomes 1:2.4. Vascular tortuosity is also seen. Similarly, superficial striate and flame shaped hemorrhages are seen in the retinal periphery. Even papilloedema has been observed. Several observers have claimed that there is no significant change in intraocular pressure ${ }^{1}$.

The retina is one of the most metabolically active tissues in the human body and retinal blood flow is tightly regulated by tissue oxygen tension $\left(\mathrm{PO}_{2}\right)^{2,3,4,5}$.

The earliest organic changes in altitude sickness is vasodilatation in the retina becoming apparent at $12,000 \mathrm{ft}(3658 \mathrm{~m})$ and reaching its maximum at $18,000 \mathrm{ft}(5486 \mathrm{~m})$ together with a slight rise in the general blood pressure and a relative rise of tension in central retinal artery 1 .

In the present study, vascular engorgement was present in $73 \%$ cases, vascular tortuosity in $49.5 \%$ cases, arterio-venous ratio change was present in $29.5 \%$ and even retinal hemorrhages 
has been observed in 5.9\% cases. Papilledema was not found in the present study.Vascular engorgement with tortuosity, a $24 \%$ increase in arterial diameter and a $23 \%$ increase in venous diameter were observed in a study of 15 members of a mountaineering expedition to Dhaulagiri, Nepal (elevation, $8,167 \mathrm{~m})^{7}$. Dilated and tortuous vessels were present in $20.9 \%$ of cases in a study by Thapa et al conducted at an altitude of 2860 meters $^{8}$.

Acute exposure to altitude caused a statistically significant but clinically insignificant increase in IOP in a study by Somner et $\mathrm{al}^{9}$. In the present study, there was no significant change in intraocular pressure at high altitude.

Cataract has been observed in mice exposed to altitudes of $30,000 \mathrm{ft}(9144 \mathrm{~m})$. Pupillary dilatation has been observed in acute hypoxia ${ }^{1}$. In the present study, the prevalence of cataract was $19.8 \%$ and pseudophakia was $17.1 \%$. However, pupilary measurement was not done in the present study.

Motor functions are rapidly impaired at high altitude. There is a tendency towards esophoria. Esotropia with diplopia is common above $12,000 \mathrm{ft}$ (3658 $\mathrm{m}$ ). In the present study, esophoria for distance was more than for near. Functional changes in vision are more common due to failure in cerebration. Visual acuity is decreased by $6 \%$ at $12000 \mathrm{ft}(3658 \mathrm{~m})$ and by $12 \%$ above $12000 \mathrm{ft}(3658 \mathrm{~m})^{1}$.

Functional changes in vision are more common at high altitudes. Scano et al cited in DukeElder $\mathrm{S}$ found a decrease of $6 \%$ of visual acuity at $12,000 \mathrm{ft} .(3658 \mathrm{~m})$ and of $12 \%$ above this; but the vision becomes normal within 10 minutes with an adequate supply of oxygen ${ }^{10}$.

Rate and extend of dark adaptation is impaired. Peripheral constriction of visual field has also been found. Regarding color vision, above 10000-12000 ft (3048 - $3658 \mathrm{~m})$, color appears MJSBH Vol 15 Issue 2 July-Dec 2016 less saturated. Latent period for development of after images is increased and eventually abolished. Regarding the higher visual function, stereoscopic vision is depressed and may be abolished ${ }^{1}$. There was no significant change in streoacuity at high altitude in the present study as confounding factors like cataract and cataract related decrease in visual acuity were not ruled out on statistical analysis.

Studies by Davis et al and Willmann et al have shown deterioration in color vision at altitudes above 3,000 meters. Tritan color vision axis (blue cones, TA) are more susceptible to hypoxic insult than protan axis (red cones, PA) ${ }^{11,12}$. These studies have been conducted at photopic conditions; whereas many military operations take place in mesopic (dim light) conditions. The prevalence of abnormal color vision was $45.1 \%$ in the present study. This could be due to high altitude as optic disc and macular pathology had been ruled out in these cases.

Mountaineers at altitude higher than $12,000 \mathrm{ft}$ $(3658 \mathrm{~m})$ are subject to retinal hemorrhages, probably secondary to hypoxic vasodilatation combined with sudden rises in intravascular pressures. The hemorrhages usually resolve spontaneously with return of visual acuity on return of the climber to lower altitude. A case of a climber on an ascent of Mount Everest at an altitude of $19386 \mathrm{ft}(5909 \mathrm{~m})$ had been reported who had a permanent visual loss to counting fingers after an ischemic central retinal vein occlusion with vitreous hemorrhage ${ }^{13}$. In the present study conducted among people living at high altitude, retinal hemorrhages were found in $5.9 \%$.

The essential defect in the atmosphere at high altitude is the lack of oxygen which at all levels retains its relative pressure of $1 / 5^{\text {th }}$ of the 
total, at $18,000 \mathrm{ft}(5486 \mathrm{~m})$, the atmospheric pressure falls to $1 / 2$ of its value at sea level ${ }^{14}$.

The general symptom of anoxia depends on the rapidity with which low barometric pressure is reached as well as on small extraneous factors as cold, exertion and so on. The first effect is seen in the functioning of the brain: judgment is impaired, mental processes are slowed, muscular coordination fails and unconsciousness supervenes particularly if muscular exercise consumes the depleted stores of oxygen available. The great vulnerability of nervous tissue to anoxia may be explained by the unusually high oxygen consumption of the brain ${ }^{15,16,17}$. Even with acclimatized men some of these effects become apparent above 17,000 ft (5182 m). However, the maximum altitude in our study was 12,666 $\mathrm{ft}(3860 \mathrm{~m})$ and such effects were not seen.

The prevalence of the pterygium in Tibetan population at high altitude is significantly high, particularly in certain at-risk group ${ }^{6}$. In the present study prevalence of pterygium was $39.6 \%$ and there was increasing trend in the prevalence of pterygium according to altitude.

\section{CONCLUSION}

Diseases like cataract was prevalent in $19.8 \%$, pseudophakia in $17.1 \%$, pterygium in $36.6 \%$, color vision defect in $45.1 \%$. Similarly, vascular engorgement in 73\%, vascular tortuosity in $49.5 \%$, a-v ratio change in $19.5 \%$ and retinal hemorrhages in $5.9 \%$. The prevalence of pterygium was in increasing trend with the rise in altitude which was statistically significant.

\section{ACKNOWLEDGEMENT}

Authors would like to thank Joseph L. Thaler for supporting the study. Similarly, we would like to thank Maggie Shah, Mukunda Poudel, Dr. Pooja Karki, Dr. Shrijana Shrestha, Dr. Anu Gurung and Late Dr. Samten Tenzing for the technical support. We would also like to thank Mr. Karna for computer works.

\section{REFERENCES}

1. Sharma RC. Ocular manifestations of high altitude. Indian J Ophthalmol 1981; 29:262-2.

2. Anderson B Jr and Saltzman H A. Retinal oxygen utilization measured by hyperbaric blackout.Arch Ophthalmol 1964; 72: 792-795.

3. lam A. and Bill A. The oxygen supply to the retina. I. Effects of changes in intraocular and arterial blood presures; and in arteial $\mathrm{PO} 2$ and $\mathrm{PCO} 3$ on the oxygen tension in the vitreous body of the cat. Acta Physiol Scand 1972; 84: 261-274.

4. Eperon G, Johnson M, David NJ. The effect of arterial PO2 on relative retinal blood flow in monkeys. Investig Ophthalmol 1975; 4:342-352.

5. Papst N, Demant E, Niemeyer G. Changes in $\mathrm{PO} 2$ induced retinal autoregulation in vitro. Graefe's Arch Clin Exper Ophthalmol 1982; 219: 6-10.

6. Lu P, Chen X, Kang Y, Ke L, Wei X, Zhang W. Pterygium in Tibetans: A populationbased study in China. Clin Experiment Ophthalmol 2007; 35:828-33.

7. Rennie D, Morrissey J. Retinal changes in Himalayan Climbers. Arch Ophthalmol 1975; 93(6):395- 400.

8. Thapa R, Paudyal G, Crandall AS, Tabin G. Vitreo-retinal disorders at high altitude in Nepal. Nepal J Ophthalmol 2013; 5(9): 57-62.

9. Somner JEA, Morris DS, Scott KM et al. What happens to intraocular presure at high altitude? IOVS 2007; 48(4):1622-1626.

10. Scano, Bietti and Schupfer. Rev Med. Aero 1947; 10: 4. In: Duke-Elder Sir S. System of Ophthalmology. London, Henry Kimpton Publishers, 1972. Vol XIV, Part II: 1208 $-1217$. 
11. Davies AJ, Morris DS, Kalson NS, Wright $\mathrm{AD}$, Imray $\mathrm{CH}$, Hogg CR. Changes to color vision on exposure to high altitude. J.R. Army Med. Corps 2011; 157(1):107-9.

12. Willmann G, Ivanov IV, Fischer MD, Lahiri S, Pokharel RK, Werner A, Khurana TS. Effects on colour discrimination during long term exposure to high altitudes on $\mathrm{Mt}$ Everest. British Journal of Ophthalmology 2010; 94(10):1393-7.

13. Vinger PF. Sports Injuries. In: Albert D, Jakobiec F (2nd ed). Principles and Practice of Ophthalmology: Philadelphia, WB Saunders Company, 2000: Vol (6), 52505261.

14. Duke-Elder Sir S. System of Ophthalmology. Vol XIV, Part II: 1208 -1217. London: Henry Kimpton Publishers; 1972.

15. Himwich H E, Nahum L H. The respiratory quotient of the brain. American Journal of Physiology-Legacy Content 1932; 101(3), 446-453.

16. Handley C A, Sweeney HM, Scherman Q, Severance R. Metabolism of the perfused dog's brain. American Journal of Physiology-Legacy Content 1943; 140(2): 190-196.

17. Elliot KAC and Henry M. Studies of the metabolism of brain suspensions III. Respiration at low oxygen tensions. J Biol Chem 1946; 163:353-359. 